Article

\title{
Applying Machine Strength Grading System to Round Timber Used in Hydraulic Engineering Works
}

\author{
Michela Nocetti ${ }^{1, * \mathbb{D}}$, Giovanni Aminti ${ }^{1}$, C. Brand Wessels ${ }^{2}$ and Michele Brunetti ${ }^{1}$ \\ 1 CNR IBE, Institute of Bioeconomy, 50019 Sesto Fiorentino, Italy; giovanni.aminti@ibe.cnr.it (G.A.); \\ michele.brunetti@cnr.it (M.B.) \\ 2 Department of Wood Science, Stellenbosch University, 7599 Stellenbosch, South Africa; cbw@sun.ac.za \\ * Correspondence: michela.nocetti@cnr.it
}

Citation: Nocetti, M.; Aminti, G.; Wessels, C.B.; Brunetti, M. Applying Machine Strength Grading System to Round Timber Used in Hydraulic Engineering Works. Forests 2021, 12, 281. https://doi.org/10.3390/ f12030281

Academic Editor: Samuel L. Zelinka

Received: 28 January 2021

Accepted: 23 February 2021

Published: 28 February 2021

Publisher's Note: MDPI stays neutral with regard to jurisdictional claims in published maps and institutional affiliations.

Copyright: (c) 2021 by the authors. Licensee MDPI, Basel, Switzerland. This article is an open access article distributed under the terms and conditions of the Creative Commons Attribution (CC BY) license (https:// creativecommons.org/licenses/by/ $4.0 /)$.

\begin{abstract}
Round timber is often used for hydraulic engineering works, but the strength grading of round logs is not as well developed as that of sawn timber. The advantages of using defined strength classes, as well as the proper selection of the raw material, could be applicable to hydraulic works as well. In this study, the methods and rules developed for sawn timber were applied to the mechanical selection of oak round logs, paying particular attention to the issue of the simplicity of grading operations and the moisture content of the timber. Both the acoustic velocity and dynamic modulus of elasticity of oak logs were measured with different instruments before performing destructive bending tests; machine settings were derived for both properties and dry and wet grading operations were simulated to compare efficiency. The use of the dynamic modulus of elasticity makes machine grading more efficient. On the other hand, the use of acoustic velocity alone is feasible and makes the procedure much faster, even if wet grading resulted in very conservative estimations. The yields obtained were similar for lower grades, but to achieve higher strength classes, the dynamic modulus was preferable. For very fast and less expensive measurements, velocity could be considered an appropriate method, as an improvement over the use of unselected material.
\end{abstract}

Keywords: wood properties; pole; oak; wood promotion; roundwood

\section{Introduction}

Round timber is considered an important resource in wooden construction. It was widely used in the past and it is experiencing a rejuvenation due to the increased focus on sustainability and the role of natural resources in combating climate change [1].

When dealing with round wood, a central topic is the exploitation of small-diameter trees, often unsuitable for sawn timber production and thus of low market value. Considering that these trees shall be cut down profitably to ensure proper forest management, the potential use of the material obtained from them in the wood construction sector thus assumes an economic importance that should not be underestimated [2].

In the same way, the use of wood in hydraulic engineering works has a long history and a great potential for present and future applications [3]. Round wood is widely used in this sector-even large-dimension logs-but due to poor characterization of the raw material, the over-engineering of structures is often a solution, both of the size and number of elements used.

Whatever the structural use of round timber, its inclusion in the strength grading system, as it is regulated in the European technical standardization, would allow for this product the advantages inherent in the better knowledge of the raw material and the possibility to select and group the resource according to its mechanical quality [4]. In particular, both greater efficiency of use and considerable economic savings could be achieved by an optimization of design, which takes advantage of the reliable estimation of the material properties summed up in the strength class system. 
However, the strength grading of round logs is not as developed as for sawn timber and, in Europe, the technical standardization on strength grading is focused on the assortments with rectangular cross-section.

There are two methods to strength-grade the structural timber: Visual and machine grading. Briefly, the first system is based on the visually detectable characteristics of the timber that affect its physical and mechanical properties (knots, slope of grain, etc.); machine grading can directly measure several wood properties (e.g., dynamic modulus of elasticity) to predict its strength, stiffness, and density [5].

Previous studies have analyzed the possibility and effectiveness of strength grading round timber, mainly by visual methods [6-11]. Some attempts have also been made with machine grading, but only to investigate the effectiveness of predicting the mechanical properties of wood by nondestructive measurements $[6,9,12]$. A complete grading procedure was not applied. The most used parameter for such an estimate has been the dynamic modulus of elasticity calculated with the determination of the frequency or the velocity of stress waves propagating along the timber piece. Overall, the achievement of the cited works was the general lower efficiency of visual grading when compared to machine determinations and the confidence in the real possibility to apply machine grading to round timber [6,9-13].

Given all the above, the present work aims to apply the technology and rules developed for sawn timber to the mechanical selection of round logs that will be used in hydraulic works. The goal is to verify the development of machine settings following the standardized procedure already established for sawn timber. Particular attention is paid to the issue of the simplicity of grading operations and the moisture content of the timber: Logs that must be used immersed in water or, in any case, in environments with very high humidity are not dried, and the selection is made fresh.

\section{Materials and Methods}

\subsection{Sampling, Measurements, and Destructive Tests}

In total, 257 oak logs were included in the sample. The logs were $4.5 \mathrm{~m}$ long and had a nominal diameter at a middle length of $220 \mathrm{~mm}$.

Before destructive tests, all the pieces underwent measurements by two instruments. By using a Strength Grading Machine (ViSCAN portable by MiCROTEC, named hereafter as SGM) certified in Europe for sawn timber, the natural frequency of vibration in the longitudinal direction after a percussion was measured and, combining it with the weight and the dimensions of the piece, the dynamic modulus of elasticity was calculated (Equation (1)). The volume of each piece was computed as the volume of a cylinder with a diameter equal to the average of the two orthogonal diameters measured at a half-length and length equal to those of the piece.

$$
E_{d y n}=\rho(2 l f)^{2}
$$

where: $E_{d y n}=$ dynamic modulus of elasticity; $\rho=$ density calculated as the weight of the whole piece to its volume; $l=$ length of the $\log ; f=$ frequency.

At the same time, the acoustic velocity after percussion was determined by another commercial instrument used mostly as a tool to evaluate the quality of logs (HITMAN HM200 by fiber-gen, hereafter named as LT, log tool).

From an operational point of view, the main differences between the two instruments can be summarized as follows: LT is of reduced size and weight and can be hand-held by the operator during the measurement; SGM, on the other hand, is portable but not handheld, and is typically used on timber specimens placed on supports and free to vibrate.

Both return data are useful for determining the dynamic modulus of elasticity, but for the present work, we want to compare the easiest working procedure (velocity measured on logs with hand-held device) to a better performing property (the dynamic modulus) determined by a machine certified for structural timber. 
After the measurements of the weight and the dimensions of each piece, and the recording of the data collected by the two instruments, four-point bending tests were carried out. The static modulus of elasticity and the bending strength were determined following the procedure provided by the European standard for structural round timber EN 14251 [14]. Briefly, the test piece was symmetrically loaded over a span of 18 times its nominal diameter at the mid-span, with the loading placed at the third points of the span. The deformation was measured in the central third on both faces at the neutral axis at the mid-point of a gauge length 5 times the nominal diameter. The average of the two measurements was used to calculate the slope of the straight section of the loaddeformation curve. The modulus of elasticity was calculated as follows:

$$
E_{m}=\frac{a l_{1}^{2} S}{16 I}
$$

where $E_{m}=$ static modulus of elasticity; $a$ = distance between the loading point and the support; $l_{1}$ = gauge length; $S$ = slope of the load-deformation curve; $I=$ second moment of area of elliptical section at mid-span.

Equation (2) differs from that of the EN 14251 [14], but in the case of tapered elements, it returns slightly underestimated values [8], thus in favor of safety for the purposes of the present work.

After the determination of the modulus of elasticity, the test went on to failure and the maximum load reached was recorded. The bending strength was calculated as follows:

$$
f_{m}=\frac{16 F_{\max } a}{\pi d_{h} d_{v}^{2}}
$$

where $f_{m}=$ bending strength; $F_{\max }=$ maximum load; $d_{h}=$ diameter perpendicular to the load direction at mid-span (horizontal); $d_{v}=$ diameter in the direction of the load at mid-span (vertical).

Following testing, density and moisture content were determined in accordance with ISO 13061-2 [15] and EN 13183-1 [16] (oven dry method), respectively. For this purpose, a small specimen of full cross-section and $7 \mathrm{~cm}$ thick was cut from each wooden element. The small pieces were weighed immediately after the destructive test and measured to calculate their volume, and then oven-dried and weighed again, thus obtaining the moisture content of wood at the time of test.

\subsection{Data Analysis}

The processing of the data obtained from the tests was carried out in accordance with the European standardization for the strength grading of solid wood with a rectangular cross-section [17]. In particular, the bending strength of each specimen was adjusted to the reference height of $150 \mathrm{~mm}$, i.e., it was divided by the factor $k_{h}=\left(150 / d_{v}\right)^{0.2}$, with $d_{v}$ the diameter in the direction of the load application at mid-span.

As required by the standard EN 384 [18] density, the modulus of elasticity and the determinations from the machines (dynamic modulus and velocity) were adjusted to the reference moisture content $(12 \%)$, applying the adjustment factors provided by Nocetti et al. [19] for timber pieces with a moisture content above the fiber saturation point.

Descriptive statistics were calculated for the properties measured by the two instruments and during the laboratory tests.

Correlations between all the properties were determined by means of linear regression analysis.

Finally, machine settings were derived according to the European standards EN 14081-2 [17] for the two instruments, and the yields (number of pieces assigned to the several classes) were compared.

The derivation of settings is briefly described in the following. The machine grading concept requires a fitting of the machine to the material to be graded. The machine settings 
are basically thresholds for the property measured by the machine (i.e., the dynamic modulus of elasticity for the SGM and the acoustic velocity for the LT in the present work) set to group the sampled pieces into strength classes. Specific verifications are then applied to validate such thresholds. The control provides three subsequent steps, described below.

The first step requires that the characteristic values of the bending strength, modulus of elasticity, and density determined in the laboratory by destructive tests meet the values tabled for the strength classes to which the timber pieces are assigned by the machine.

In the second step, the same verification is done individually for at least 4 sub-samples. Therefore, the round logs were divided into 4 groups (QA, QB, QC, QD) according to the supply over time (Table 1). Each group was smaller than the number required by the official procedure (about 70 pieces in each group against the minimum of 100 required), but for demonstration purposes, the procedure can also work with a smaller sampling.

Table 1. Mean values and coefficients of variation (CV) of physical and mechanical properties for the 4 groups of round logs (QA, QB, QC, QD) defined according to the supply over time. $\mathrm{MC}_{\mathrm{m}}=$ mean moisture content, $f_{m, m}=$ mean bending strength; $f_{m, k}=5$ th percentile of bending strength; $E_{m, 0, m}=$ mean static modulus of elasticity; $V_{m}=$ mean velocity; $E_{d y n, m}=$ mean dynamic modulus of elasticity; $\rho_{m}=$ mean density; $\rho_{k}=5$ th percentile of density.

\begin{tabular}{|c|c|c|c|c|c|c|}
\hline \multirow[t]{2}{*}{ Property } & \multirow[t]{2}{*}{ Unit } & \multicolumn{4}{|c|}{ Group } & \multirow[t]{2}{*}{ ALL } \\
\hline & & QA & QB & $\mathrm{QC}$ & QD & \\
\hline $\mathrm{N}$ & $(-)$ & 71 & 72 & 72 & 42 & 257 \\
\hline $\mathrm{MC}_{\mathrm{m}}$ & $(\%)$ & 56.7 & 62.6 & 62.5 & 62.5 & 60.9 \\
\hline $\mathrm{CV}$ & $(\%)$ & 17 & 15 & 17 & 18 & 17 \\
\hline$f_{m, m}$ & $(\mathrm{MPa})$ & 56.3 & 63.7 & 68.2 & 67.7 & 63.6 \\
\hline$f_{m, k}$ & $(\mathrm{MPa})$ & 34.0 & 45.0 & 46.0 & 49.5 & 43.1 \\
\hline $\mathrm{CV}$ & $(\%)$ & 21 & 17 & 16 & 16 & 19 \\
\hline$E_{m, 0, m}$ & (GPa) & 11.2 & 12.8 & 13.5 & 13.2 & 12.6 \\
\hline $\mathrm{CV}$ & $(\%)$ & 23 & 19 & 18 & 19 & 21 \\
\hline$V_{m}$ & $(\mathrm{~km} / \mathrm{s})$ & 4.3 & 4.6 & 4.5 & 4.5 & 4.5 \\
\hline $\mathrm{CV}$ & $(\%)$ & 7 & 5 & 6 & 7 & 7 \\
\hline$E_{d y n, m}$ & $(\mathrm{MPa})$ & 12.7 & 14.2 & 14.6 & 14.4 & 13.9 \\
\hline $\mathrm{CV}$ & $(\%)$ & 20 & 14 & 16 & 15 & 17 \\
\hline$\rho_{m}$ & $\left(\mathrm{~kg} / \mathrm{m}^{3}\right)$ & 666 & 674 & 686 & 703 & 680 \\
\hline$\rho_{k}$ & $\left(\mathrm{~kg} / \mathrm{m}^{3}\right)$ & 601 & 573 & 627 & 653 & 610 \\
\hline $\mathrm{CV}$ & $(\%)$ & 7 & 6 & 5 & 4 & 6 \\
\hline
\end{tabular}

Finally, a cost analysis is performed. It compares the assignment to a class made by the machine with the optimum grading, that is, the assignment based on timber mechanical properties determined by the laboratory destructive tests described above. Specific weighting factors are applied for wrongly graded pieces; particularly, adverse factors are given for incorrectly upgraded pieces.

The required characteristic values of the strength classes are reported in EN 338 [20], while the methods to calculate the characteristic values are described in EN 14358 [21] and EN 384 [18].

For the calculations, the local modulus of elasticity was used, as it does not need any adjustment for shear stresses as the global one does [22]. 


\section{Results and Discussion}

\subsection{Properties of the Raw Material}

The mean values and the coefficients of variation of the physical and mechanical properties determined in the laboratory for the sampled material are reported in Table 1. It must be mentioned that the moisture content was very high. The logs had large dimensions (nominal diameter of $220 \mathrm{~mm}$ ) and were intended for hydraulic engineering works, to be loaded immersed in water or in very high humidity conditions. Therefore, no drying process is usually performed.

However, as explained in the methods, to comply with the strength class system of structural wood, the design values are reported at the reference condition of $12 \%$. The only exception is the bending strength, for which, despite being affected by the moisture content of the timber, no adjustment is required by the standard [18]. As timber with higher moisture content has lower strength [23], the material strength is underestimated when testing fresh material, i.e., above the fiber saturation point.

Comparison of the average properties is possible with data reported in the literature for sawn oak timber. An overview on oak (sawn pieces with rectangular cross-section) of European origin (France and Germany) presented similar values of the modulus of elasticity, but the strength was generally lower for sawn pieces in respect of what was measured in the present work (from 46 to $52 \mathrm{MPa}$ compared to $64 \mathrm{MPa}$ listed in Table 1), despite a far higher density (higher than $710 \mathrm{~kg} / \mathrm{m}^{3}$ compared to our $680 \mathrm{~kg} / \mathrm{m}^{3}$ ) [24-26].

The higher strength is even more remarkable, keeping in mind that our value refers to fresh material, with high moisture content and no adjustment. Indeed, previous works have shown that the mechanical strength of round timber was greater than the corresponding squared assortments cut from the same material. Clearly, the continuity of the fibers plays a decisive role in giving greater strength to the wooden element $[27,28]$. For some species, the characteristic bending strength used in design standards is up to $500 \%$ higher than that of the sawn timber of the same species (i.e., SANS 10163-1 [29]).

The relationships between the properties determined by the bending test and by the two instruments are reported in Table 2. The values are comparable or higher to what is usually observed for sawn timber of oak [26,30] or chestnut [31,32], for which machine grading has already been developed both in dry and wet conditions [32].

Table 2. Coefficients of determination between properties $\left(f_{m}=\right.$ bending strength; $E_{m}=$ static modulus of elasticity; $\rho=$ density; $V=$ velocity; $E_{d y n}=$ dynamic modulus of elasticity).

\begin{tabular}{ccccc}
\hline & $f_{m}$ & $E_{m}$ & $\rho$ & $V$ \\
\hline$E_{m}$ & 0.72 & & & \\
\hline$\rho$ & 0.35 & 0.31 & & \\
\hline$V$ & 0.35 & 0.49 & 0.06 & 0.56 \\
\hline$E_{d y n}$ & 0.60 & 0.77 & 0.29 & \\
\hline
\end{tabular}

The property with the weakest correlations is density. This is a common outcome of studies dealing with the prediction of the structural properties of hardwoods [32-34]: Density is poorly correlated with strength and stiffness, as well as with the nondestructive determinations with the exception of what measures density directly (e.g., scales or X-rays).

Between the two measures made by the machines, velocity and dynamic modulus, the latter, as expected, correlates best with the different properties of the material.

\subsection{Machine Settings}

Settings were calculated both for velocity and dynamic modulus of elasticity. The requirements to be met for a batch to be assigned to a particular strength class are listed in Table 3 (only the classes used in the study are included). 
Table 3. Strength class properties as described in EN 338 [20] $\left(f_{m, k}=5\right.$ th percentile of bending strength; $E_{m}=$ mean modulus of elasticity; $\rho_{k}=5$ th percentile of density).

\begin{tabular}{cccc}
\hline & $\begin{array}{c}f_{m, k} \\
(\mathbf{M P a})\end{array}$ & $\begin{array}{c}E_{m} \\
(\mathbf{G P a})\end{array}$ & $\begin{array}{c}\rho_{k} \\
\left.\mathbf{( k g / \mathbf { m } ^ { 3 }}\right)\end{array}$ \\
\hline D50 & 50 & 14.0 & 620 \\
\hline D45 & 45 & 13.5 & 580 \\
\hline D40 & 40 & 13.0 & 550 \\
\hline D35 & 35 & 12.0 & 540 \\
\hline D30 & 30 & 11.0 & 530 \\
\hline
\end{tabular}

Table 4 reports the settings developed for both the velocity and the dynamic modulus of elasticity for several strength class combinations. The comparison is performed by the yields achieved with the two instruments and with the optimum grading (the grading based on the "real" properties of the material determined by destructive tests).

Table 4. Settings and yields for the optimum grading (based on the real properties determined by destructive tests) and machine grading for several grade combinations ( $\mathrm{R}=$ rejects).

\begin{tabular}{cccccc}
\hline Grade & Optimum & \multicolumn{2}{c}{ Velocity } & \multicolumn{2}{c}{$E_{\text {dyn }}$} \\
\hline Comb. & Grading Yield (\%) & $\begin{array}{c}\text { Setting } \\
\mathbf{( k m} / \mathbf{s})\end{array}$ & $\begin{array}{c}\text { Yield } \\
\mathbf{( \% )}\end{array}$ & $\begin{array}{c}\text { Setting } \\
\mathbf{( M P a )}\end{array}$ & $\begin{array}{c}\text { Yield } \\
\mathbf{( \% )}\end{array}$ \\
\hline D35 & 100 & 3.78 & 97.7 & 8750 & 98.1 \\
R & 0 & & 2.3 & & 1.9 \\
\hline D40 & 100 & 4.03 & 92.6 & 9490 & 94.9 \\
R & 0 & & 7.4 & & 5.1 \\
\hline D45 & 96.1 & 4.27 & 73.9 & 11,000 & 88.7 \\
R & 4.9 & & 26.1 & & 11.3 \\
\hline D50 & 84.8 & - & - & 12,400 & 74.7 \\
R & 15.2 & - & - & & 25.3 \\
\hline D45 & 96.1 & 4.501 & 51.0 & 13,5001 & 59.9 \\
D30 & 0 & 3.78 & 46.7 & 8750 & 38.1 \\
R & 4.9 & & 2.3 & & 1.9 \\
\hline D50 & 84.8 & - & - & 13,5001 & 59.9 \\
D30 & 0 & - & - & 8750 & 38.1 \\
R & 15.2 & - & - & & 1.9 \\
\hline
\end{tabular}

${ }^{1}$ Setting increased to allow class D30 and to minimize rejects.

For the low grades (D35 or D40), the settings were easily determined and the yields were very similar when using the velocity or the dynamic modulus. However, as the classes increased, the yields reachable when the velocity was the property used for the selection were lower if compared to the use of the dynamic modulus. Some grade combinations were even not possible to sort (D50), as the velocity was not effective enough for the derivation of settings. Similar findings were reported for chestnut sawn timber [32].

During the development of settings, the sub-sample QA often affected negatively the results: i.e., the thresholds needed to increase to meet the second step of the verification process (requirements met in each sub-sample), as the mechanical properties of QA were lower than the others (Table 1).

Among the material properties, stiffness was the limiting one for the grading. Figure 1 shows the ratio between the characteristic values achieved by the pieces assigned to a class by the machine (in the figure, only the strength grading machine using the dynamic modulus of elasticity as grading property) and the values required for strength, stiffness, and density. The strength and the density were always well above the requirements (ratio 
far higher than 1), while the modulus of elasticity presented the lowest ratio, i.e., the characteristic values were close to the requirement. Strength and density also got closer to the characteristic values of the class only for the highest class (D50). Similar results were observed when the velocity was used as the grading property.

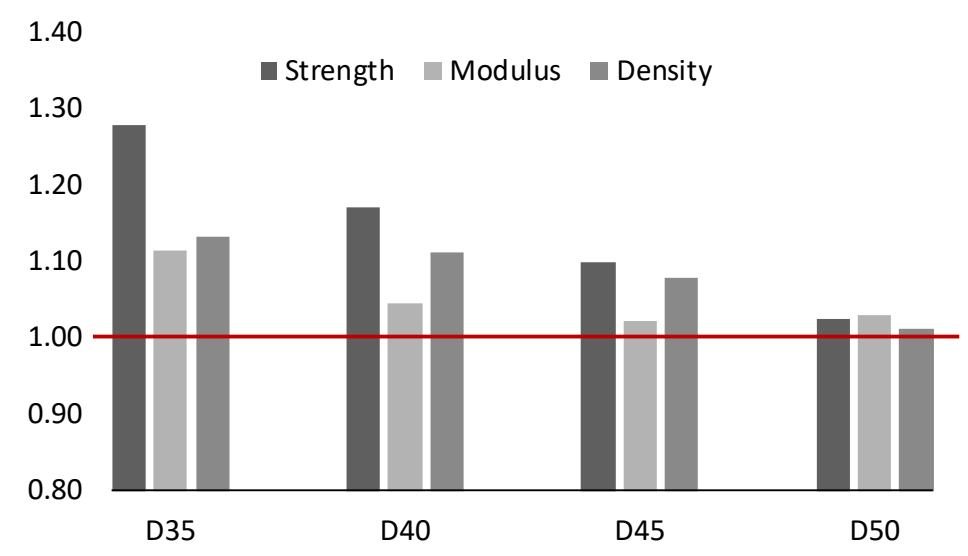

Figure 1. Ratio between the characteristic values achieved by the pieces graded by machine (using the dynamic modulus of elasticity) and the requirements for the classes (combinations with only one class).

In the same way, previous works on softwoods observed that stiffness was the limiting factor to the assignment of round logs to the strength class systems $[7,8]$.

Although, during grading, the velocity proved to be less efficient than the dynamic modulus of elasticity in terms of yields, the effectiveness of separating the material into quality groups was very similar between the two properties, except for density. The dynamic modulus of elasticity separated only slightly better strength and stiffness (Figure 2), but no separation at all was noticed in the groups formed by velocity in terms of density (Figure 2).

The explanation is clearly found in the correlation between the acoustic velocity and the density of the material, which was close to zero. What is remarkable, however, is the good separation of the mechanical properties that was obtained despite the correlations with the velocity being much lower than those with the dynamic modulus of elasticity (Table 2).

\subsection{Pratical Application of Settings}

In practice, the round material used for hydraulic works is selected green, i.e., with high values of moisture content (usually above the fiber saturation point), while the settings derived and reported here were adjusted to the reference values of $12 \%$. Their practical application differs because the velocity decreases with moisture, even above the wood fiber saturation point, while the dynamic modulus of elasticity remains constant [19].

This means that the use of velocity as a grading property requires the measurement of the moisture content of fresh wood (which is known to be difficult) to allow the proper adjustment of the values recorded during grading. On the contrary, an accurate determination of the moisture content of wet material is not necessary for the dynamic modulus of elasticity. The only check to be made is that the material is above the fiber saturation point; a constant factor is then applied for the adjustment [19]. On the other hand, the dynamic modulus of elasticity requires the determination of the wood density and therefore the need to weigh the piece and to measure its dimensions.

Assuming the moisture content of round fresh wood of at least higher than $40 \%$ (our sample had on average a MC of $60 \%$ and only one log had MC $<40 \%$ ), it could be possible to re-adjust the velocity settings to a moisture content value of $40 \%$ and apply them to our sample to simulate a grading made in practice without correction for moisture (the 
measured velocity on fresh timber would be lower than if measured at $40 \%$ of moisture; therefore, the procedure would be less efficient but safe).
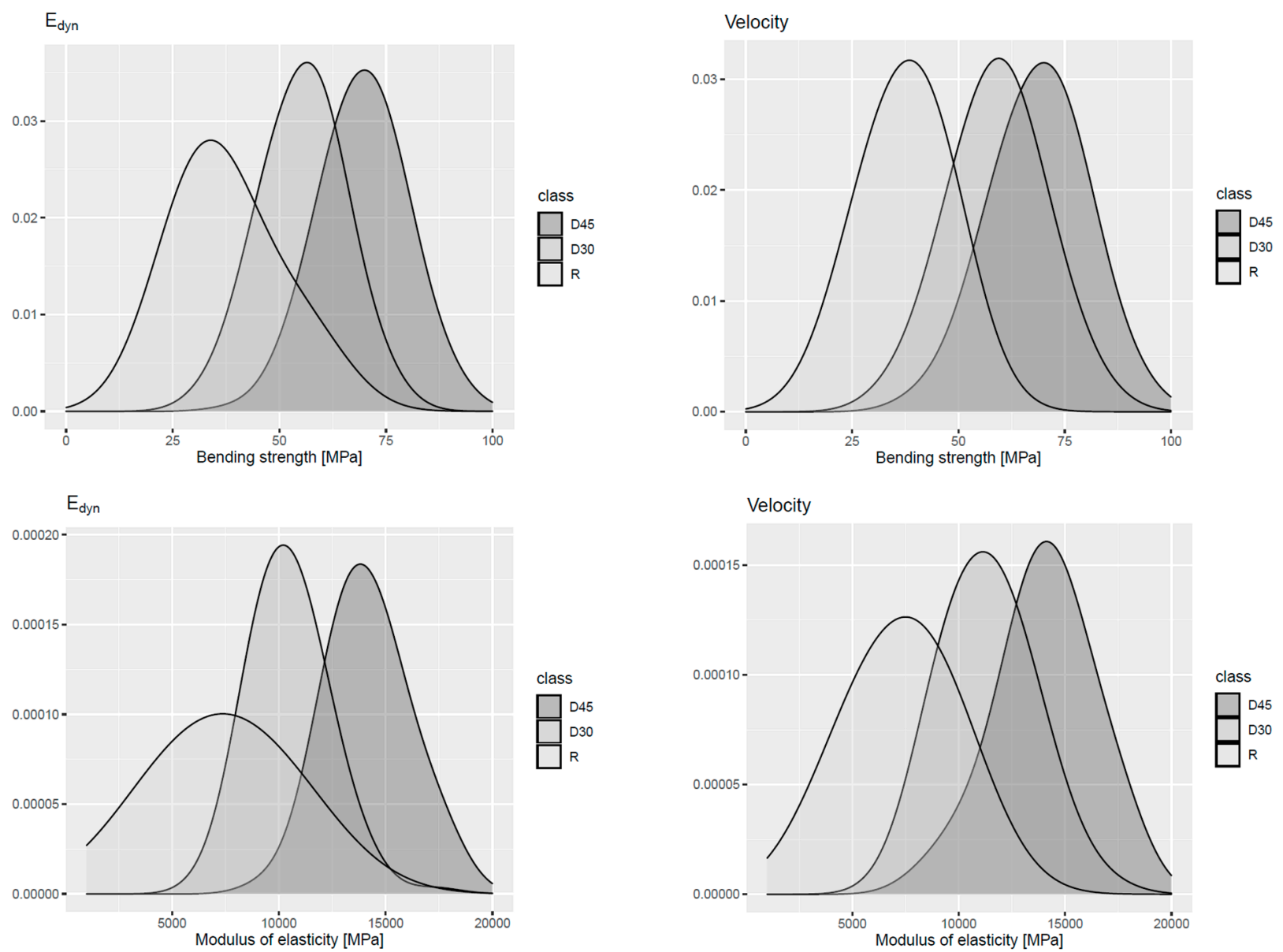

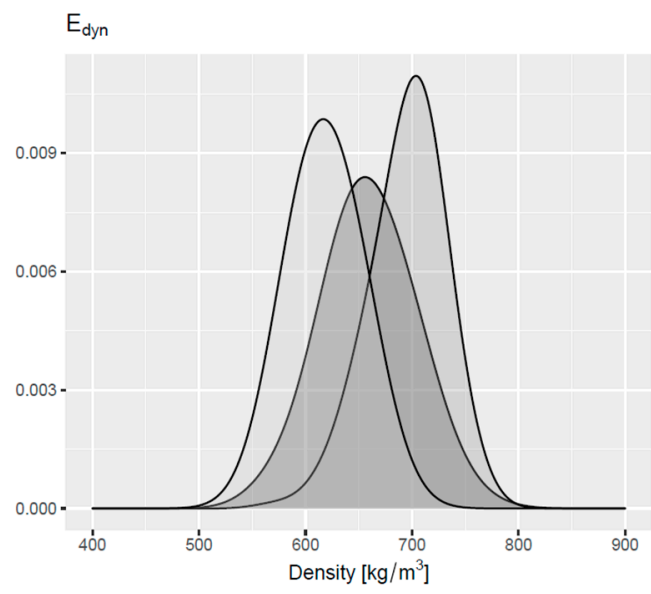

(a)

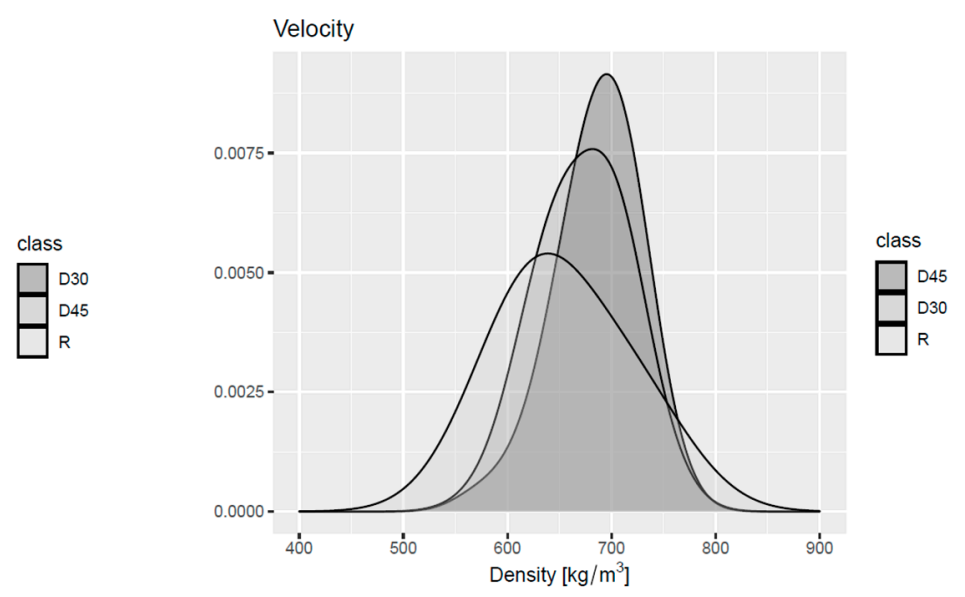

(b)

Figure 2. Density curves for bending strength, modulus of elasticity, and wood density of the three classes (D45-D30-R) sorted by the machine grading, by the dynamic modulus of elasticity (a) and the velocity (b).

Of course, the yields decreased (Table 5) more for the high classes in which the material must be assigned: The yield achieved was $87.9 \%$ for D35-R (9.8\% less than dry grading), $64.6 \%$ for D40-REJ ( $23.7 \%$ less), and only $43.2 \%$ for D45-R (30\% less). However, the grading remained formally correct (Figures 3-5). In the figures, the examples of the wet grading of D35-R and D45-R are represented graphically. For strength and density, only 1 or 2 pieces 
(therefore, less than the 5\%) were lower than the characteristic values of the classes. In the same way, the requirement for the modulus of elasticity was always fulfilled as the mean values for the pieces assigned to a strength class was higher than the value tabled for the same class (dashed line in the figures).

Table 5. Yields achieved by wet grading, using the velocity unadjusted for moisture content.

\begin{tabular}{ccccc}
\hline Yield & $\begin{array}{c}\text { D35/R } \\
\mathbf{( \% )}\end{array}$ & $\begin{array}{c}\text { D40/R } \\
\mathbf{( \% )}\end{array}$ & $\begin{array}{c}\text { D45/R } \\
\mathbf{( \% )}\end{array}$ & $\begin{array}{c}\text { D45/D30/R } \\
\mathbf{( \% )}\end{array}$ \\
\hline Class & 87.9 & 68.9 & 43.2 & $12.8 / 75.1$ \\
Rejects & 12.1 & 31.1 & 56.8 & 12.1 \\
\hline
\end{tabular}

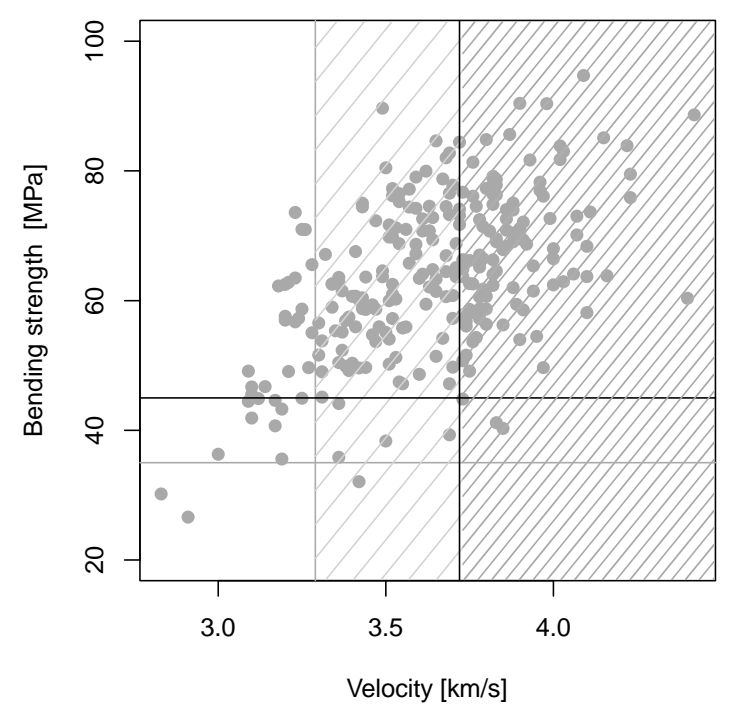

Figure 3. Scatterplot of bending strength vs. velocity measured on wet timber and not adjusted for moisture content. Vertical lines = settings recalculated at 40\% MC for D35 (grey) and D45 (black); horizontal lines $=$ characteristic values of strength for the classes D35 (grey) and D45 (black); sparse oblique lines = pieces assigned to D35; dense oblique lines = pieces assigned to D45.

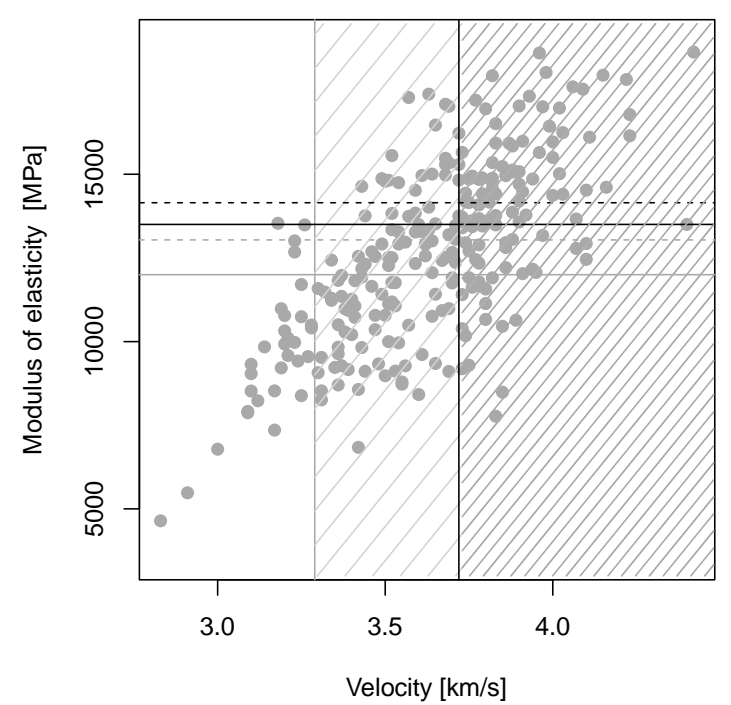

Figure 4. Scatterplot of static modulus of elasticity vs. velocity measured on wet timber and not adjusted for moisture content. Vertical lines $=$ settings recalculated at $40 \% \mathrm{MC}$ for D35 (grey) and D45 (black); solid horizontal lines = mean values of modulus for the classes D35 (grey) and D45 (black); dashed horizontal lines = mean values of modulus of pieces assigned to D35 (grey) and D45 (black); sparse oblique lines = pieces assigned to D35; dense oblique lines = pieces assigned to D45. 


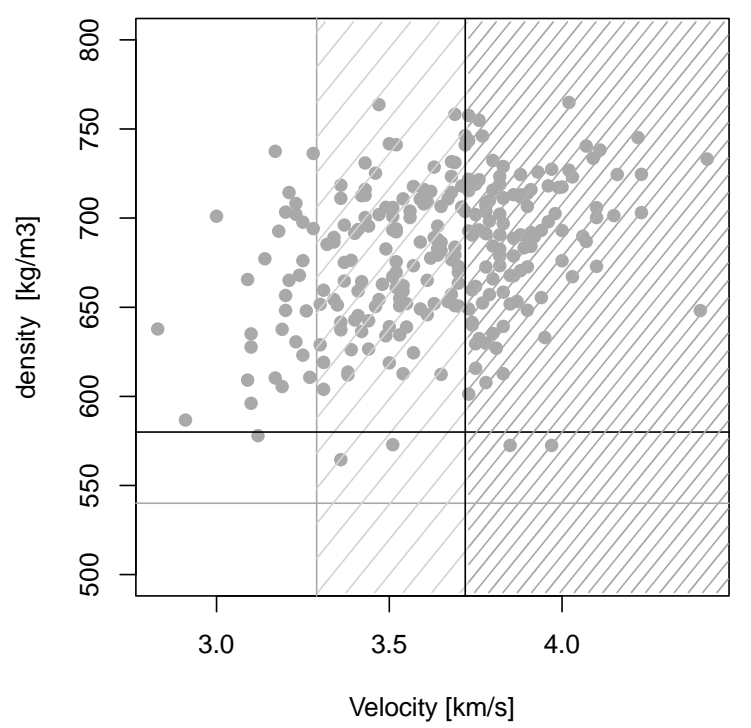

Figure 5. Scatterplot of density vs. velocity measured on wet timber and not adjusted for moisture content. Vertical lines = settings recalculated at 40\% MC for D35 (grey) and D45 (black); horizontal lines $=$ characteristics values of density for the classes D35 (grey) and D45 (black); sparse oblique lines = pieces assigned to D35; dense oblique lines = pieces assigned to D45.

\section{Conclusions}

Machine strength grading was verified to be possible and can be effectively applied to round timber, mostly with the same rules used for the squared assortments.

The settings developed in the present work should be considered merely demonstrative due to the insufficient initial sampling (less than the number required by the technical standardization). However, the calculations and verifications required by the machine grading system were all fulfilled as proof that the method can be effectively applied to round wood.

The limiting property for assigning the material to the strength class system was the stiffness. This, together with the mechanical characterization of the round material, led to two relevant conclusions. On one side, the strength classes as defined for squared sawn wood do not fit appropriately to round timber, for which the bending strength was higher than those of rectangular pieces with a similar modulus of elasticity. An adaptation of the strength class profiles could allow a more accurate description of the round material. On the other hand, wanting to keep the class system described by the current standardization unchanged, an estimate as accurate as possible of the modulus of elasticity might improve the effectiveness of the grading of round wood.

Evidently, the use of the dynamic modulus of elasticity makes machine grading more efficient in terms of better yields and high quality classes that can be selected. It is also applicable on fresh material (moisture content above the wood fiber saturation point).

On the other hand, the use of acoustic velocity alone is feasible and makes the procedure much faster, with the need of less variables to be measured. The yields achieved are only a little lower than those obtained by the dynamic modulus, but the highest class (D50) could not be selected. In the case of wet grading (grading done on fresh material), the velocity could also be used without the need of further adjustments (no need for accurate measurement of the moisture content of green timber), if conservative assumptions are made, i.e., moisture content of the timber above $40 \%$. In this way, wet grading resulted in very conservative estimations. It can be stated that if the grading aims at selecting material in low classes (D30, D35, or D40), the acoustic velocity measured on wet timber might be a valid alternative. If higher classes are the target, the yield could be too low for profitable use. However, a technical and economical evaluation should be carried out of the advantages of using a very fast and relatively cheap tool to what is usually an unsorted material. 
In conclusion, the advantages of extending the strength grading procedure of squared sawn timber to round logs used in hydraulic works has potential.

Author Contributions: Conceptualization, M.B.; methodology, M.B., M.N. and C.B.W.; investigation, M.B., M.N. and G.A.; data curation, M.N.; writing—original draft preparation, M.N., G.A. and C.B.W.; writing—review and editing, M.B., M.N., G.A. and C.B.W.; funding acquisition, M.B. All authors have read and agreed to the published version of the manuscript.

Funding: The achievements were possible thanks to the collaboration and the financing of the Autonomous Region Friuli Venezia Giulia, Italy.

Institutional Review Board Statement: Not applicable.

Informed Consent Statement: Not applicable.

Data Availability Statement: 3rd Party Data.

Acknowledgments: The authors are thankful to Paolo Burato, Polo Pestelli and Graziano Sani for the invaluable help during the laboratory tests.

Conflicts of Interest: The authors declare no conflict of interest.

\section{References}

1. Bukauskas, A.; Mayencourt, P.; Shepherd, P.; Sharma, B.; Mueller, C.; Walker, P.; Bregulla, J. Whole Timber Construction: A State of the Art Review. Constr. Build. Mater. 2019, 213, 748-769. [CrossRef]

2. Ranta-Maunus, A. Round Small-Diameter Timber for Construction; Final Report of Project FAIR CT 95-0091; VTT Technical Research Centre of Finland: Espoo, Finland, 1999; p. 191.

3. van Amstel, H.P. Wood in Hydraulic Engineering. In Tropical Hardwood Utilization: Practice and Prospects; Oldeman, R.A.A., Fontaine, R.G., Guillard, J.P., Brazier, J.D., Menon, K.D., Overbeek, A., Eds.; Forestry Sciences; Springer: Dordrecht, The Netherlands, 1982; Volume 3, pp. 387-391, ISBN 978-90-481-8271-8.

4. Ridley-Ellis, D.; Stapel, P.; Baño, V. Strength Grading of Sawn Timber in Europe: An Explanation for Engineers and Researchers. Eur. J. Wood Prod. 2016, 74, 291-306. [CrossRef]

5. Brunetti, M.; Burato, P.; Cremonini, C.; Negro, F.; Nocetti, M.; Zanuttini, R. Visual and Machine Grading of Larch (Larix Decidua Mill.) Structural Timber from the Italian Alps. Mater Struct. 2016, 49, 2681-2688. [CrossRef]

6. Green, D.W.; Gorman, T.M.; Evans, J.W.; Murphy, J.F. Mechanical Grading of Round Timber Beams. J. Mater. Civ. Eng. 2006, 18, 1-10. [CrossRef]

7. Fernández-Golfín, J.I.; Diez Barra, M.R.; Hermoso, E.; Mier, R. Mechanical Characterization of Visually Classified, Small-Diameter Laricio Pine Round Timber. Span. J. Agric. Res. 2007, 5, 304-311. [CrossRef]

8. Vestøl, G.I.; Høibø, O. Bending Strength and Modulus of Elasticity of Pinus Sylvestris Round Timber from Southern Norway. Scand. J. For. Res. 2010, 25, 185-195. [CrossRef]

9. Morgado, T.F.; Dias, A.M.; Machado, J.S.; Negrão, J.H.; Marques, A.F. Grading of Portuguese Maritime Pine Small-Diameter Roundwood. J. Mater. Civ. Eng. 2017, 29, 04016209. [CrossRef]

10. Aira, J.R.; Villanueva, J.L.; Lafuente, E. Visual and Machine Grading of Small Diameter Machined Round Pinus Sylvestris and Pinus Nigra Subsp. Salzmannii Wood from Mature Spanish Forests. Mater. Struct. 2019, 52, 32. [CrossRef]

11. Vega, A.; González, L.; Fernández, I.; González, P. Grading and Mechanical Characterization of Small-Diameter Round Chestnut (Castanea Sativa Mill.) Timber from Thinning Operations. Wood Mater. Sci. Eng. 2019, 14, 81-87. [CrossRef]

12. Green, D.W.; Gorman, T.M.; Evans, J.W.; Murphy, J.F. Improved Grading System for Structural Logs for Log Homes. For. Prod. J. 2004, 54, 52-62.

13. Vries, P.D.; Gard, W. The Development of a Strength Grading System for Small Diameter Roundwood. Heron 1998, 43, $183-198$.

14. EN 14251. Structural Round Timber-Test Methods; CEN_European Committee for Standardization: Brussels, Belgium, 2012.

15. ISO 13061-2. Physical and Mechanical Properties of Wood. Test Methods for Small Clear Specimen. Part 2: Determination of Density for Physical and Mechanical Tests; ISO_-International Organization for Standardization: Geneve, Switzerland, 2014.

16. EN 13183-1. Moisture Content of a Piece of Sawn Timber. Determination by Oven Dry Method; CEN-European Committee for Standardization: Brussels, Belgium, 2002.

17. EN 14081-2. Timber Structures. Strength Graded Structural Timber with Rectangular Cross Section. Part 2: Machine Grading; Additional Requirements for Type Testing; CEN_European Committee for Standardization: Brussels, Belgium, 2018.

18. EN 384. Structural Timber. Determination of Characteristic Values of Mechanical Properties and Density; CEN-European Committee for Standardization: Brussels, Belgium, 2016.

19. Nocetti, M.; Brunetti, M.; Bacher, M. Effect of Moisture Content on the Flexural Properties and Dynamic Modulus of Elasticity of Dimension Chestnut Timber. Eur. J. Wood Prod. 2015, 73, 51-60. [CrossRef]

20. EN 338. Structural Timber. Strength Classes; CEN_European Committee for Standardization: Brussels, Belgium, 2016. 
21. EN 14358. Timber Structures. Calculation and Verification of Characteristic Values; CEN-European Committee for Standardization: Brussels, Belgium, 2016.

22. Nocetti, M.; Brancheriau, L.; Bacher, M.; Brunetti, M.; Crivellaro, A. Relationship between Local and Global Modulus of Elasticity in Bending and Its Consequence on Structural Timber Grading. Eur. J. Wood Prod. 2013, 71, 297-308. [CrossRef]

23. Ido, H.; Nagao, H.; Kato, H.; Miura, S. Strength Properties and Effect of Moisture Content on the Bending and Compressive Strength Parallel to the Grain of Sugi (Cryptomeria Japonica) Round Timber. J. Wood Sci. 2013, 59, 67-72. [CrossRef]

24. Glos, P.; Denzler, J.K. Allocation of Central European Hardwoods into EN 1912. In Proceedings of the CIB W18, Meeting 39, Florence, Italy, 28-31 August 2006. Paper 39-6-1.

25. Lanvin, J.-D.; Reuling, D.; Costrel, Y.; Ducerf, J. Evaluation of French Oak for Structural Use. In Proceedings of the 1st International Scientific Conference on Hardwood Processing (ISCHP), Québec City, QC, Canada, 15-17 September 2007; pp. 61-65.

26. Faydi, Y.; Brancheriau, L.; Pot, G.; Collet, R. Prediction of Oak Wood Mechanical Properties Based on the Statistical Exploitation of Vibrational Response. BioResources 2017, 12, 5913-5927. [CrossRef]

27. Sandoz, J. Form and Treatment Effects on Conical Roundwood Tested in Bending. Wood Sci. Technol. 1991, 25, 203-214. [CrossRef]

28. Vestøl, G.I.; Høibø, O. Bending Strength and Modulus of Elasticity of Squares with Wane as Compared with Round Timber of Scots Pine (Pinus Sylvestris). For. Prod. J. 2010, 60, 40-47. [CrossRef]

29. SANS 10163-1. South African National Standard. The Structural Use of Timber. Part 1: Limit-States Design; Standards South Africa: Pretoria, South Africa, 2003.

30. Kretschmann, D.E.; Green, D.W. Mechanical Grading of Oak Timbers. J. Mater. Civ. Eng. 1999, 11, 91-97. [CrossRef]

31. Vega, A.; Dieste, A.; Guaita, M.; Majada, J.; Baño, V. Modelling of the Mechanical Properties of Castanea Sativa Mill. Structural Timber by a Combination of Non-Destructive Variables and Visual Grading Parameters. Eur. J. Wood Prod. 2012, 70, 839-844. [CrossRef]

32. Nocetti, M.; Brunetti, M.; Bacher, M. Efficiency of the Machine Grading of Chestnut Structural Timber: Prediction of Strength Classes by Dry and Wet Measurements. Mater. Struct. 2016, 49, 4439-4450. [CrossRef]

33. Nocetti, M.; Bacher, M.; Brunetti, M.; Crivellaro, A.; van de Kuilen, J.W.G. Machine Grading of Italian Structural Timber: Preliminary Results on Different Wood Species. In Proceedings of the World Conference on Timber Engineering, WCTE, Riva del Garda, Italy, 20-24 June 2010; pp. 285-292.

34. Brunetti, M.; Nocetti, M.; Pizzo, B.; Aminti, G.; Cremonini, C.; Negro, F.; Zanuttini, R.; Romagnoli, M.; Scarascia Mugnozza, G. Structural Products Made of Beech Wood: Quality Assessment of the Raw Material. Eur. J. Wood Prod. 2020, 78, 961-970. [CrossRef] 